\title{
IMPLEMENTASI SOSIAL MEDIA MARKETING DALAM MENINGKATKAN JARINGAN PASAR
}

\author{
Nina Valentika' ${ }^{1)}$, Tsarina Zenabia ${ }^{2)}$, Muslim $^{3)}$, Nanik Ida Rosini ${ }^{4)}$, Nining $^{5)}$ \\ ${ }^{1,4}$ Program Studi Matematika, Fakultas Matematika dan Ilmu Pengetahuan Alam, Universitas Pamulang \\ ${ }^{2,3}$ Program Studi Akuntansi S1, Fakultas Ekonomi, Universitas Pamulang \\ ${ }^{5}$ Program Studi Hukum S1, Fakultas Hukum, Universitas Pamulang
}

\begin{abstract}
Abstrak
Sosial media sekarang telah memiliki peran penting dalam strategi pemasaran bagi bisnis kecil maupun besar. Kini berbagi informasi kepada pengunjung atau follower bukan satusatunya keuntungan menggunakan sosial media bagi sebuah bisnis. Jauh lebih yang utama adalah agar produk kita laku dipasar dan banyak diminati pelanggan. Mitra dalam program kegiatan Pengabdian Kepada Masyarakat (PKM) ini adalah salah satu pelaku usaha yang berada di Rangkapan Jaya Depok, Jawa Barat. Pelaku usaha mengeluhkan soal penjualan produk "Mie Depok" yang sulit serta omset yang semakin menurun. Hal ini disebabkan banyaknya kompetitor / pelaku usaha lain yang menjajakan produk yang sama serta minimnya strategi pemasaran. Dalam kegiatan PKM kali ini kami para dosen dan mahasiswa dari Universitas Pamulang mencoba membantu mitra pelaku usaha untuk mengembangkan metode pemasaran melalui social media yang ada seperti, Facebook, Instagram maupun situs belanja online Bukalapak. Diharapkan dengan pelatihan dan penyuluhan penggunakan social media sebagai alat bantu pemasaran dapat meningkatkan penjualan produk "Mie Depok" dan mengurangi permasalahan menurunnya omset penjualan dari pelaku usaha.
\end{abstract}

Kata Kunci: Media Sosial, Pemasaran

\begin{abstract}
Social media now has an important role in marketing strategies for small and large businesses. Now sharing information with visitors or followers is not the only advantage of using social media for business. Much more, the main thing is that our products sell well in the market and are in great demand by customers. A partner in the Community Service (PKM) program is one of the business actors located in Rangkap Jaya Depok, West Java. Business operators have complained about the difficult sales of "Mie Depok" products and the declining turnover. This is due to a large number of competitors / other business actors selling the same product and the lack of marketing strategies. In this PKM activity, lecturers and students from Pamulang University try to help business partners to develop marketing methods through existing social media such as Facebook, Instagram, and the online shopping site Bukalapak. It is hoped that training and counseling on the use of social media as a marketing tool can increase sales of "Mie Depok" products and reduce the problem of decreasing sales turnover from business actors.
\end{abstract}

Keywords: Social Media, Marketing

Correspondence author: Nina Valentika, dosen02339@unpam.ac.id, Depok, Indonesia 


\section{PENDAHULUAN}

Pemasaran merupakan elemen penting dalam menjalankan sebuah bisnis. Banyak pelaku bisnis yang meluangkan waktunya untuk memikirkan metode/ cara/ strategi pemasaran apa yang tepat agar barang yang dijualnya laku di pasaran dan omsetnya cepat meningkat. Hal ini berpengaruh terhadap sukses tidaknya bisnis karena bergantung pada metode/ cara pemasarannya.

Bagi seorang pengusaha/ pebisnis, salesman atau tenaga pemasaran adalah merupakan ujung tombak dari keberhasilan suatu bisnis disamping produk yang baik dan juga keunggulan kompetitif lainnya. Salesman harus mampu mendatangkan pembeli potensial yang melakukan pembelian terhadap barang dan jasa yang dijual. Permasalahannya saat ini adalah jika pelaku bisnis menggunakan pemasaran secara konvensional dengan merekrut para salesman maka dampak yang timbul adalah pelaku bisnis harus membebankan biaya gaji bagi para salesman nya. Hal inilah yang memberatkan para pelaku usaha kecil menengah, disatu sisi para pelaku UKM yang merupakan sokoguru pengembangan masyarakat mandiri dan mengurangi jumlah pengangguran, disisi lain pelaku bisnis harus juga menyediakan modal yang besar dengan menggaji para salesman pemasaran untuk kemajuan usahanya.

Solusi strategi pemasaran yang bersifat konvensional dengan menggunakan tenaga pemasaran / salesman adalah dengan menggunakan social media, sosial media sekarang telah memiliki peran penting dalam strategi pemasaran bagi bisnis kecil maupun besar. Kini berbagi informasi seputar produk dapat diberikan kepada pengunjung atau follower melalui social media, sebagai contoh Facebook, Instagram ataupun situs penjualan online lainnya. Bertambahnya jenis sosial media yang semakin bervariasi, mulai dari sosial media personal, blog, bahkan eCommerce juga turut mendukung berkembangnya perjalanan bisnis tersebut.

Namun solusi pemasaran secara digital online masih menemui kendala, kendala yang dijumpai saat ini adalah banyak pelaku bisnis yang masih gagap tehonologi meskipun mampu membeli sebuah smartphone dan kurang menguasai tehnologi pembuatan web. Terdapat beberapa penelitian dan teori mengenai e-commerce dan media sosial. Hasil penelitian Maulana et.al. (2015) adalah implementasi e-commerce dengan menggunakan software opencart pada toko Pastbrik Malang akan dapat membantu mengurangi biaya yang dikeluarkan serta dapat menyampaikan informasi secara detail dan cepat mengenai produk kepada pelanggan. Hasil Penelitian Romdonny (2018) adalah peran media sosial sangat membantu dalam memasarkan produk bola sepak yang diproduksi PT. Sinjaraga Santika Sport Majalengka dan meningkatkan angka penjualan. Hasil penelitian Prihadi (2018) adalah kemampuan e-commerce berpengaruh tidak signifikan terhadap kinerja pemasaran pedagang, promosi di media sosial berpengaruh signifikan terhadap kinerja pemasaran pedagang dan kemampuan ecommerce dan promosi di media sosial secara simultan berpengaruh signifikan terhadap kinerja pemasaran pedagang. Menurut Gunelius S (2018), peubah kesuksesan social media marketing adalah content creator (konten dibuat menarik), content sharing (konten dibagikan kepada komunitas sosial), connecting (jaringan luas membangun hubungan untuk menghasilkan banyak bisnis) dan community building (membangun komunitas di Internet). Sehingga, sangatlah penting dilakukan pelatihan pemasaran secara online dengan memanfaatkan media sosial pada Usaha Kecil dan Menengah (UKM) di Indonesia guna meningkatkan hasil penjualan mitra. Pelatihan dilakukan 
dengan menggunakan beberapa peubah kesuksesan social media marketing yang dicetuskan oleh Gunelius S (2018).

Berdasarkan permasalahan mitra, kami dari Universitas Pamulang mengadakan Pengadian Kepada Masyarakat (PKM) pada para pelaku UKM "Mie Depok" di daerah Rangkapan Jaya, Depok. Berdasarkan uraian masalah yang dihadapi mitra, maka disepakati bahwa terdapat masalah utama, yaitu: pemasaran online. Kegiatan Pemasaran Online yang saat ini mitra aplikasikan ialah hanya dalam bentuk beriklan di status whatsapp, beriklan di grup whatsapp, beriklan di facebook dan instagram. Kegiatan pemasaran berbasis online yang demikian belum memiliki daya serap pembeli yang cukup optimal, sehingga tidak jarang Usaha Ibu Veronica merasa bahwa omsetnya belum stabil. Solusi yang kami berikan ialah dengan memberikan pelatihan teknis kegiatan pemasaran online secara intensif. Kanalisasi pemasaran online juga di tambah, tidak hanya pada whatsapp, ataupun social media lainnya, seperti facebook dan instagram, tetapi juga optimalisasi layanan e-commerce seperti Bukalapak.

\section{METODE PELAKSANAAN}

Kegiatan Pengabdian Kepada Masyarakat (PKM) dilaksanakan di Kelurahan Rangakapan Jaya Kecamatan Pancoran Mas, Kota Depok pada hari Jum'at, Sabtu dan Minggu tanggal 5 - 6 Oktober 2019. Komunitas social media terdiri dari beberapa pelaku usaha tersebar beberapa tempat di Kota Depok, Jawa Barat. Komunitas social media mewadahi beberapa kecamatan di Kota Depok yang memiliki persoalan kompleks. Fokus kami saat ini ialah pada 1 kecamatan di Kota Depok, yaitu Rangkapan Jaya Depok. Para pelaku usaha mengeluhkan soal penjualan produk yang menurun serta banyaknya kompetitor yang menggunakan layanan online juga berdampak terhadap penjualan produk dan pendapatan omset para pelaku usaha.

Tahap Implementasi/ pelaksanaan kegiatan adalah sesi ceramah, sesi Tanya jawab serta sesi diskusi. Pada sesi ceramah yang disampaikan oleh Bapak Muslim selaku Ketua pengsusul dan juga Narasumber membahas mengenai pentingnya berwirausaha sebagai bagian utama dari soko guru perekonomian Indonesia dan mengurangi jumlah pengangguran serta pada kesempatan tersebut juga disebutkan bahwa berwirausaha memupuk jiwa kemandirian bagi masyarakat berpenghasilan menengah ke bawah.

Pada sesi tanya jawab, membahas permasalahan omset pelaku usaha yang belum stabil, karena terdampak minimnya modal untuk menggaji tenaga pemasaran/ salesman, omset yang jauh dibawah harapan, adanya competitor yang juga menjual produk yang sama dengan pelaku usaha binaan, minimnya pengetahuan tentang aplikasi layanan online digital, penolakan pasar karena pasar sudah membeli produk yang sama pada layanan ecommerce lain.

Pada sesi diskusi, pelaku usaha binaan diberikan pemahaman tentang aplikasi yang dibutuhkan dalam pemasaran produk secara digital dan pelatihan dalam menggunakan perangkat maupun aplikasi social media, sehingga dari aplikasi digital pelaku usahan dapat membuat atau menggunakan salah satu atau beberapa situs penjualan online secara minim biaya. Program pelatihan yang didukung oleh praktisi/akademisi handal dibidang teknologi, informasi dan komunikasi, dan pelaku usaha dapat beriklan pada whatsapp, facebook, instagram, serta situs penjualam online lainnya. 


\section{HASIL DAN PEMBAHASAN}

Hasil yang telah dicapai berdasarkan pelaksanaan kegiatan Pengabdian Kepada Masyarakat (PKM) yang telah dilaksanakan dapat identifikasi sebagai berikut:

1). Mitra bisnis melakukan pemasaran menggunakan aplikasi penjualan online pada Smartphone yang dimilikinya, mitra bisnis merekrut karyawan sebagai penjaga kedai dan petugas pengirim/ delivery.

2). Petugas pengantar/ delivery, pada saat kesempatan mengantar produk petugas membawa brosur/ leaflet varian produk yang dimiliki mitra bisnis, sehingga pelanggan dapat mengetahui produk lain yang dimiliki mitra bisnis dan diharapkan pelanggan membeli produk tersebut dikemudian hari.

3). Dengan menggunakan aplikasi penjualan online yang ada di situs penjualan dan social media, terbukti mengurangi biaya tenaga pemasaran, memperluas pasar sasaran dan jaringan pasar.

4). Dengan menggunakan aplikasi online dan situs penjualan online, terbukti meminimalisir biaya gaji tenaga pemasaran dan digantikan dengan biaya modal dengan menggunakan internet dan pulsa.

5). Setelah diberikan pelatihan tentang penggunaan aplikasi online (facebook, instagram, you tube), membuat akun, menggunakan aplikasi photo editor dan video editor maka mitra bisnis dapat berkomunikasi secara online dengan pelanggan/ customer dan mendengarkan kebutuhan mereka secar realtime.

6). Disamping itu pula dari aplikasi penjualan online/ E-commerce mitra bisnis dapat melihat di kolom komentar pelanggan mitra bisnis, sehingga hal-hal yang baik tentang produk dari mitra bisnis dapat dipertahankan / mungkin ditingkatkan sedangkan hal-hal yang kurang disukai oleh pelanggan segera dapat dicarikan perbaikannya.

7). Tempat jualan online diantaranya adalah social media, membuat website sendiri dan market place. Social media diantaranya adalah facebook, twitter, instagram, pinterest, youtube, dan whatsapp. Market place diantaranya adalah lazada, bukalapak, shopee, dan tokopedia. Alasan berjualan melalui social media adalah mudah, dapat dilakukan dimanapun dan kapanpun, serta investasi dengan harga terjangkau. 


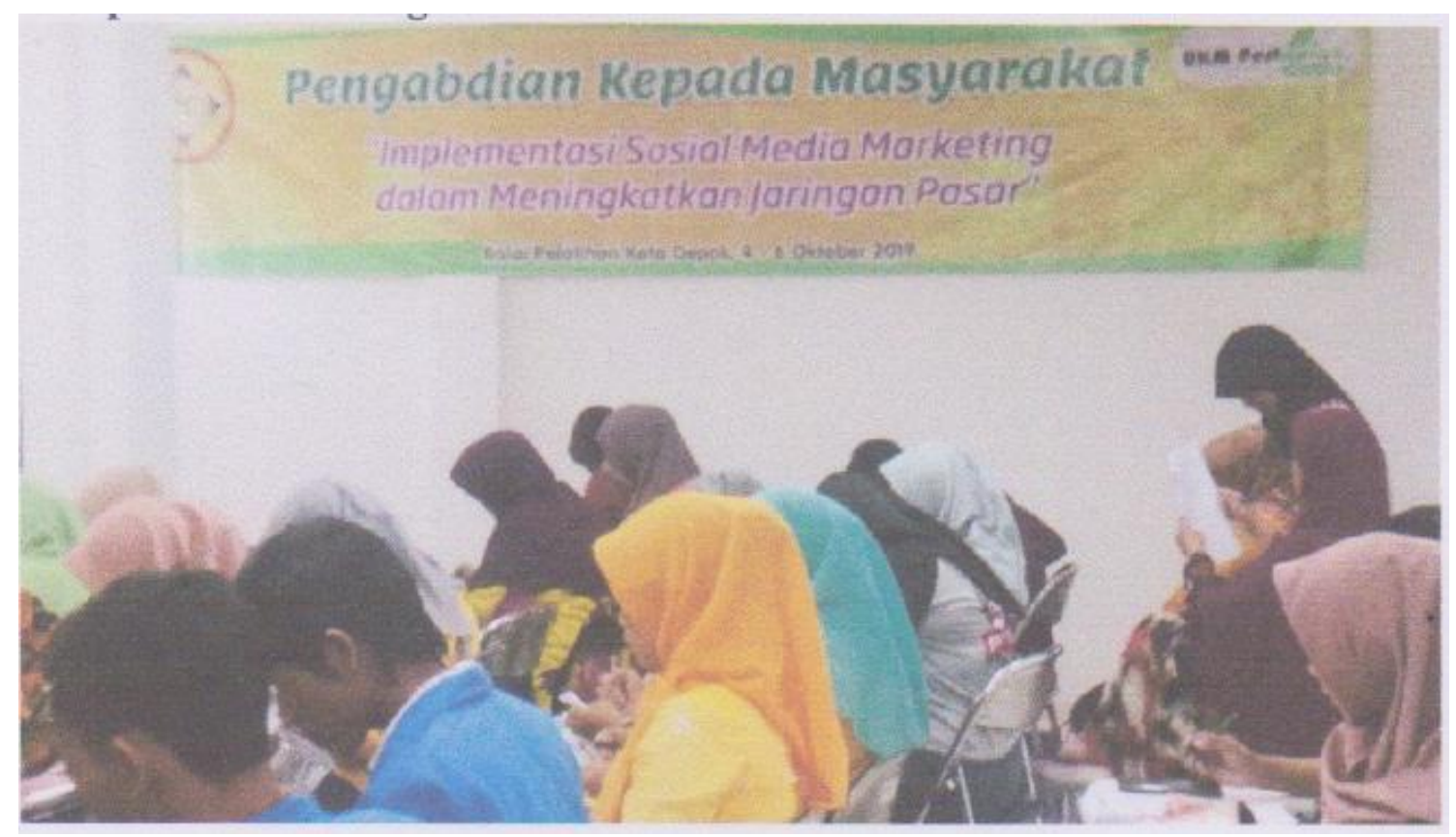

Gambar 1 Pelaksanaan Kegiatan PkM

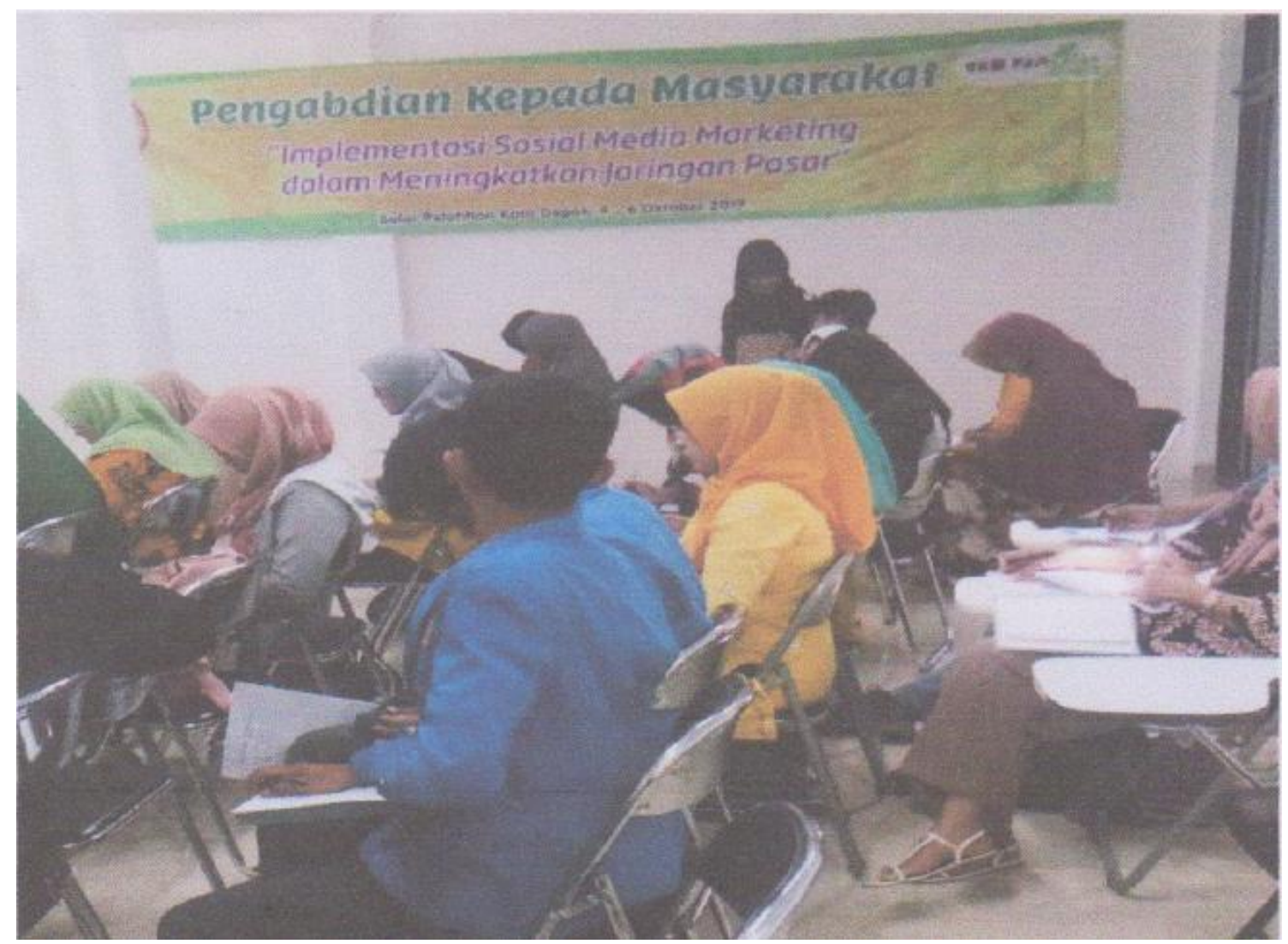

Gambar 2 Pelaksanaan Kegiatan PkM 


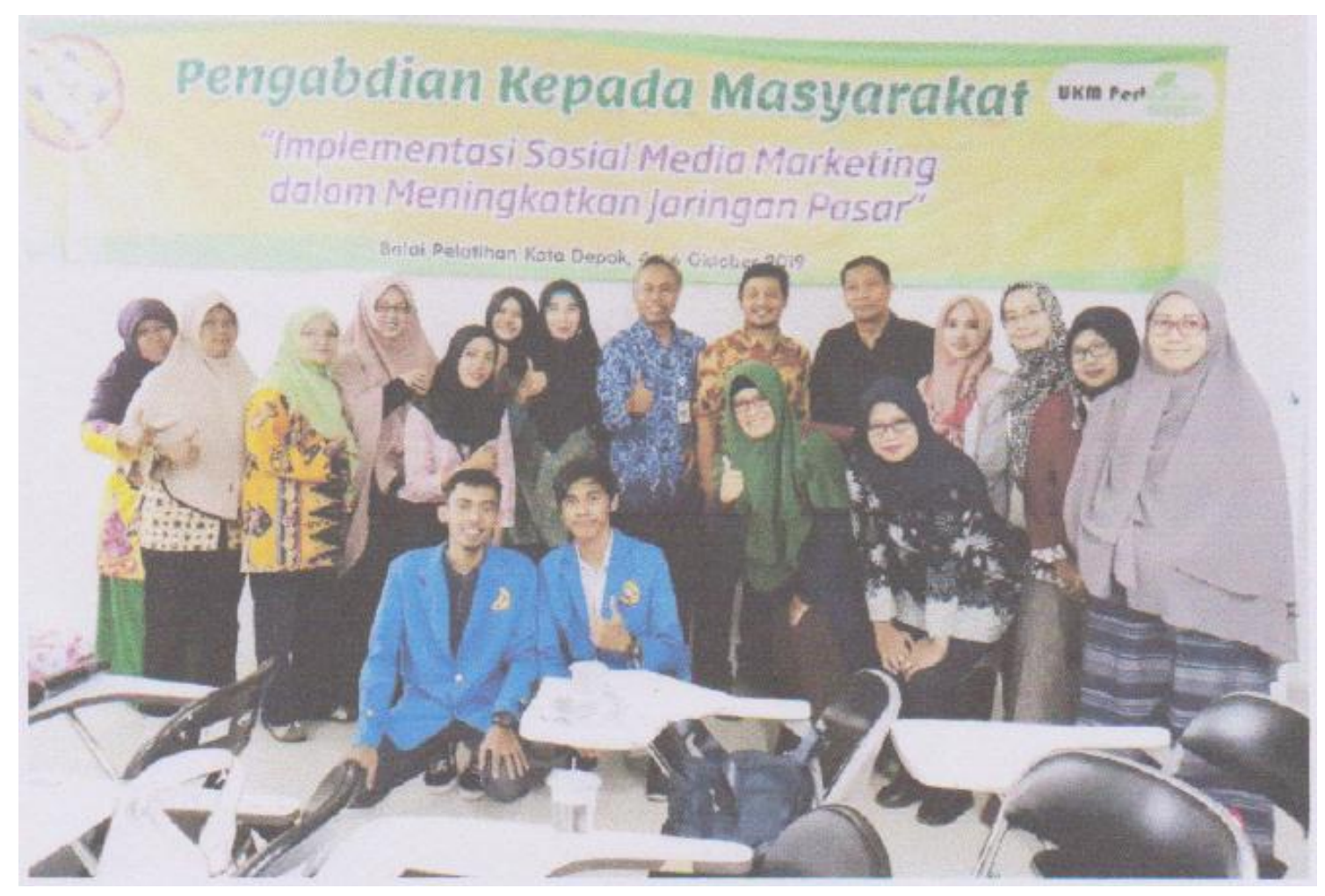

Gambar 3 Foto bersama dengan Narasumber

\section{SIMPULAN}

Kegiatan pelaksanaan Pengabdian Kepada Masyarakat (PKM) di Kelurahan Rangkapan Jaya RT 03, Kecamatan Pancoran Mas, Depok sudah dilalui, berbagai hal menarik diperoleh dari pelaksanaan kegiatan tersebut. Kegiatan PKM ini telah memberikan kontribusi kepada pelaku bisnis/mitra bisnis "Mie Depok" dengan memberikan solusi berupa pelatihan guna meningkatkan pengetahuan dalam penggunaan social media sebagai infrastruktur pemasaran produknya. Pelatihan dan penyuluhan yang diberikan kepada mitra bisnis bukan hanya seputar membuat akun penjualan online tetapi juga mitra bisnis diajarkan bagaimana cara mempost/ meng upload photo atau video produk mitra bisnis. Hal ini membuat pelanggan dan konsumen dapat terhubung secara realtime dimana mitra bisnis dapat bertemu dan mendengarkan kebutuhan pelanggan. Dengan pemasaran online mitra bisnis dapat meng update produk-produk baru, info promosi produk, mendapatkan online review dari pelanggan terkait baik dan tidaknya produk yang dipasarkan serta review atau testimonial para pelanggan dapat mempengaruhi keputusan berbelanja dari pelanggan yang lainnya yang mungkin belum pernah mencoba atau membeli produk mitra bisnis dan meningkatkan pemberdayaan mitra. 


\section{DAFTAR PUSTAKA}

Gunelius S. (2011). 30 Minute Social Media Marketing. United State: McGraw Hill.

Maulana et.al. (2015). Implementasi E-Commerce Sebagai Media Penjualan Online (Studi Kasus Pada Toko Pastbrik Kota Malang). Jurnal Administrasi Bisnis (JAB). Volume 29 Nomor 1 halaman 1-9.

Prihadi D, Susilawati AD. (2018). Pengaruh Kemampuan E-Commerce dan Promosi di Media Sosial terhadap Kinerja Pemasaran. Benefit Jurnal Manajemen dan Bisnis. Volume 3 Nomor 1 halaman 15-20.

Romdonny J, Rosmadi MLN. (2018). Peran Media Sosial dalam Mendukung Pemasaran Produk Organisasi Bisnis. Ikraith Ekonomika. Volume 1 Nomor 2 halaman 25-30. 